\title{
A MULHER QUE TRABALHA ONTEM E HOJE: QUAL A SUA CONTRIBUIÇÃO HISTÓRICA NA TRANSFORMAÇÃO DAS RELAÇÕES DE TRABALHO?
}

\author{
$\underline{\text { Juliana de Freitas Silva }}{ }^{1}$; José Raimundo Oliveira Lima ${ }^{2}$ \\ 1. Bolsista PIBIC/FAPESB, Graduanda em Economia, Universidade Estadual de Feira de Santana, \\ julysofia.freitas@gmail.com \\ 2. Orientador, Departamento de Ciências Sociais Aplicadas, Universidade Estadual de Feira de Santana, \\ zeraimundo@uefs.br
}

PALAVRAS-CHAVE: economia solidária; economia popular; economia popular e solidária; mulher negra

\section{INTRODUÇÃO}

A economia popular como uma alternativa ao desemprego, onde os trabalhadores excluídos do processo de acumulação de capital decidem produzir ou comercializar bens para geração de renda sem necessariamente realizar uma organização de grupo. Tentando obter o mesmo objetivo de geração de emprego e renda a economia solidária propõe uma organização desses sujeitos de maneira a tornar o movimento da economia popular em uma economia política dos setores populares a fim de organizar os grupos isolados numa perspectiva de redes. Essa aproximação pode ser obtida por meio das incubadoras que se propõe a desenvolver um trabalho político pedagógico que possibilita as iniciativas a se organizarem enquanto grupo produtivo autogestionário. A economia popular e solidária como economia política dos setores populares sugere uma aproximação das incubadoras com os grupos para que juntos possam criar alternativas de geração de renda de modo que o trabalho seja o fator protagonista.

Dentro desse campo de estudo de economia popular e solidária o presente trabalho se propõe a estudar questões de gênero e raça e como a economia popular e solidária lida com essas questões, tendo como objetivo analisar como a economia popular e solidaria lida com as questões de gênero e raça. $\mathrm{O}$ interesse pelo tema parte das minhas observações cotidianas, pois é notório o número de mulheres trabalhando na economia popular e solidaria e a sua maioria negra, portanto uma investigação sobre essas problemática faz-se necessário levando em consideração a história de formação do Brasil.

\section{MATERIAL E MÉTODOS OU METODOLOGIA (ou equivalente)}

Antes de explicar a metodologia adotada para o desenvolvimento da pesquisa, é necessário dizer que não existe neutralidade na pesquisa, portanto a escolha da autora pela pesquisa-ação é um posicionamento político, pretende-se realizar uma pesquisa que 
esteja relacionada com a realidade dos sujeitos que a constroem o dai-a -dia e não apenas se prender em modelos prontos da economia ortodoxa.

Portanto, a autora adota como método de pesquisa, a pesquisa- ação que é definida por THIOLLENT 2011 como sendo "a pesquisa -ação além da participação, supõe uma forma de ação planejada de caráter social, educacional, técnico ou outro que nem sempre se encontra em propostas de pesquisa participante", sendo assim o autor explica o que é pesquisa-ação e afirma que existe diferença entre a pesquisa- ação e a pesquisa participante, em que na pesquisa-ação existe a pesquisa participante embora não necessariamente na pesquisa participante existe uma ação.

Os caminhos que serão percorridos de acordo com o método adotado, na sequência de continuidade da pesquisa, para responder aos objetivos serão açõesreflexões-ações contidas no estudo de caso do grupo informal Sabores do Quilombo, originário de uma comunidade quilombola do Distrito de Feira de Santana que participa do projeto Cantina Solidária III. Para tanto será realizado uma revisão bibliográfica sobre os temas de economia solidária, economia popular e solidária, gênero e raça, bem como outros temas afins que se apresentam na pauta de incubação indicados pelo processo de pesquisa na sua forma integral.

\section{RESULTADOS E/OU DISCUSSÃO (ou Análise e discussão dos resultados)}

Entender as dimensões da economia solidária é umas das tarefas que se propõe essa pesquisa, haja vista que existem muitos conceitos sobre a Teoria de Economia Solidária e um leque de autores que estudam esse campo da pesquisa. O conceito surge na Europa como cooperativismo e o percussor é Robert Owen, e vai se espalhando pela Inglaterra e Estados Unidos. No Brasil é Paul Singer quem trás o conceito de Economia Solidária em 2003 cria-se a Secretaria Nacional de Economia Solidária (SENAES), e o conceito de Economia Solidária fica restrito apenas a uma política pública.

Segundo Singer (2002),

A economia solidária é outro modo de produção, cujos princípios básicos são a propriedade coletiva ou associada do capital e o direito à liberdade individual. A aplicação desses princípios une todos os que produzem numa única classe de trabalhadores que são possuidores de capital por igual em cada cooperativa ou sociedade econômica (SINGER,2002, p.10).

Observa-se que o conceito que Singer traz sobre economia solidária é complexo, ao afirmar que economia solidária é um modo de produção, economia solidária seria 
manifestações de outras formas de produzir, mas que está inserida em um modo de produção capitalista.

França Filho (2007) traz o conceito de economia solidária como sendo uma outra economia ligada ao terceiro setor, haja vista que ela não está totalmente inserida no mercado e também não está diretamente ligada ao Estado, sendo assim a mesma seria uma espécie de terceiro setor.

Segundo França Filho (2007),

[...] a construção conjunta de oferta e da demanda como característica chave dessa outra economia supõe, ainda, no nível de ação, uma articulação fina entre as dimensões sócio produtivas e sócio política. [...] trata-se de moradores num determinado território debatendo politicamente seus problemas comuns e decidindo seu destino (FRANÇA FILHO, 2007, p.161).

Portanto para compreender essa outra economia é necessário entender que economia está para além de mercado autorregulado como é o pressuposto da teoria neoclássica, é perceber a economia em várias dimensões e não apenas em única dimensão, a das trocas. Essa outra economia vem ganhando força na América Latina e no Brasil, pois vem ampliando o seu conceito e dimensões, para que a economia solidária não seja apenas uma forma de geração de renda é necessário reivindicar o seu caráter político e trazer para o debate as pautas dos trabalhadores e trabalhadoras, nesse sentido emerge a economia popular e solidária que segundo Lima (2016) é a economia política dos setores populares.

Segundo Lima (2016),

A economia popular e solidária apresenta-se entrelaçada ao desenvolvimento local solidário, pois os sujeitos protagonistas, agentes ou iniciativas mobilizam-se de forma articulada por um processo que os liga por laços de solidariedade, pertencimento e união na busca de organicidade que tem poder de transformação (LIMA,2016, p.9).

Portanto uma outra economia é possível quando os agentes que estão envolvidos no processo se propõe na construção de um projeto que busca a transformação da sua comunidade, e da sociedade. Nessa nova configuração de economia, qual seria a participação das mulheres nessa sociedade? É tentando responder essa pergunta que a autora se propõe a realizar uma pesquisa teórica e empírica sobre o tema, já que existe outra economia e para essa outra economia se desenvolver é necessário reivindicar outro tipo de relações sociais e de trabalho para as mulheres, 
principalmente as mulheres negras que são as mais atingidas na lógica de exclusão do sistema capitalista.

Hirata (2002) diz que apesar do progresso da situação das mulheres terem melhorado, elas ainda continuam ganhando menos que os homens e a autora atribuem essa problemática para o fato da naturalização das tarefas domesticas ficaram a cargo das mulheres.

Segundo Hirata (2002),

Um enfoque do ponto de vista das relações de gênero mostra que o problema do emprego está longe de se esgotar na consideração do mercado de trabalho. Enfim essas pesquisas mostram que era necessário atentar não apenas para o continnum trabalho assalariado formal/ remunerado/informal/domestico, mas também para as descontinuidades (alternativas e rupturas entre $\mathrm{o}$ assalariamento industrial, o trabalho ocasional, $\mathrm{o}$ trabalho informal, ou mesmo a saída do mercado de trabalho e a responsabilidade exclusiva pelo trabalho doméstico) (HIRATA,2002, p.19).

Portanto é necessário analisar essas continuidades e/ou descontinuidades daquilo que chama de "papel das mulheres", essa naturalização das funções que já estão postas pela sociedade.

Saffioti (2013) entende a inserção da mulher no mundo do trabalho capitalista como uma dupla desvantagem, a primeira na subvalorizarão das capacidades femininas e o seguindo a inclusão periférica no sistema de produção.

Segundo Saffioti (2013),

A condição da mulher nas sociedades de classes tem sido vista por numerosos estudiosos como resultado da injunção de fatores de duas ordens diversas: de ordem natural e de ordem social. Dentre os primeiros, o mais sério diria respeito ao fato de a capacidade de trabalho da mulher sofrer grande redução nos últimos meses do período de gestação e nos primeiros tempos que seguem o parto. $\mathrm{O}$ aleitamento tornaria ainda insubstituível a mãe junto à criança pequena (SAFFIOTI,2013, p.85).

Essa condição natural da mulher é usada de várias formas para justificar a sua qualificação ou posição profissional, o que causa nas mulheres frustações e incertezas em que se teve fazer escolhas a todo momento, qual profissão escolher, ser mãe ou não, a mulher a todo momento é colocada para fazer renuncias.

Outra problemática que permeia a questão de gênero é quando esse conceito está relacionado à raça, principalmente as mulheres negras, que são as mais atingidas na lógica de exclusão do sistema capitalista, Davis (2016) faz uma contextualização da 
condição das mulheres desde o sistema escravocrata até os dias atuais e aponta um direcionamento de que há uma lacuna entre as mulheres brancas e negras, principalmente quando se inicia os movimentos feministas nos Estados Unidos e muitas dessas mulheres brancas do movimento feminista se uniram a causa antiescravista.

Segundo Davis (2016),

[...] ao mesmo tempo, porém, a incipiente industrialização da economia minou o prestígio que as mulheres tinham no lar - um prestigio baseado no caráter produtivo e absolutamente essencial de seu trabalho doméstico até então. Por causa disso, a condição social das mulheres começou a se deteriorar. Uma consequência ideológica do capitalismo industrial foi o desenvolvimento de uma ideia mais rigorosa de inferioridade feminina (DAVIS,2016, p.45).

Assim, a própria ideologia de desenvolvimento do capitalismo industrial modificou a estrutura social em todas as esferas da sociedade e consequentemente as atribuições destinadas para as mulheres começaram foram questionadas, foi uma revolução de valores.

Portanto analisar a "inserção" das mulheres no mundo do trabalho requer uma ponderação, é necessário dizer quem são essas mulheres.

\section{CONSIDERAÇÕES FINAIS (ou Conclusão)}

Entender como se constrói as relações sociais em cada sociedade ao longo do tempo e como essas ocorre essas modificações é parte do oficio da (o) economista que está dentro do campo das ciências sociais aplicadas, sendo assim é compreensível que o interesse de estudar o mundo do trabalho delimitando para as questões de gênero e raça na perspectiva de outra forma de trabalho - o trabalho associado- que é campo de estudo em economia popular e solidária.

Portanto a pesquisa torna-se relevante pois se propõe a analisar as relações de gênero e raça nas iniciativas de economia popular e solidária e entender essa configuração de trabalho que está para além da geração de renda.

\section{REFERÊNCIAS}

DAVIS, Angela. Mulheres, raça e classe. 1.ed. São Paulo: Boitempo,2016.

HIRATA, Helena. Nova divisão sexual do trabalho? Um olhar voltado para a empresa e a sociedade.1. ed. São Paulo: Boitempo,2002. 
LIMA, José Raimundo O. A economia popular e solidária como estratégia para o desenvolvimento local solidário.2014.306 f. Tese (Doutorado em Educação e Contemporaneidade). Universidade do Estado da Bahia, Salvador.

LIMA, José Raimundo Oliveira. Economia Popular e Solidária e desenvolvimento local: relação protagonizada pela organicidade das iniciativas. Otra Economía, v. 10 , n. 18 , p. $3-17,2016$

SAFFIOTI, Heleieth. A mulher na sociedade de classe.3. ed. São Paulo: Expressão Popular,2013.

SINGER, Paulo. Introdução à Economia solidária-Editora Fundação Perseu Abramo, São Paulo, 2002.

THIOLLENT, Michel. Metodologia da pesquisa-ação. 18 ed. São Paulo: Cortez,2011. 